\title{
Combined Influence of Lifestyle Risk Factors on Body Fat in Spanish Adolescents - the AVENA Study
}

\author{
David Martinez-Gomez ${ }^{\mathrm{a}}$ Luis A. Moreno ${ }^{\mathrm{b}} \quad$ Javier Romeo $^{\mathrm{a}} \quad \mathrm{J}^{\text {P. Pablo Rey-López }}$ \\ Ruth Castillo $^{c}$ Maria J. Cabero ${ }^{d}$ Germán Vicente-Rodriguez ${ }^{b}$ Angel Gutiérrez ${ }^{c}$ \\ Oscar L. Veiga ${ }^{\mathrm{e}}$ Ascension Marcos ${ }^{\mathrm{a}}$, on behalf of the AVENA Study Group \\ ${ }^{a}$ Immunonutrition Research Group, Department of Metabolism and Nutrition, Institute of Food Science and Technology and \\ Nutrition (ICTAN), Spanish National Research Council (CSIC), Madrid, \\ ${ }^{\mathrm{b}}$ GENUD (Growth, Exercise, Nutrition and Development) Research Group, Zaragoza, \\ ${ }^{c}$ Department of Medical Physiology, School of Medicine, University of Granada, Granada, \\ d Department of Pediatrics, University of Cantabria, Santander, \\ e Department of Physical Education, Sport and Human Movement, Faculty of Teacher Training and Education, \\ The Autonomous University of Madrid, Madrid, Spain
}

\section{Keywords}

Obesity - Adolescence - Diet - Physical activity .

Sleep duration - Television viewing

\section{Summary}

Objective: To examine the combined influence of four lifestyle risk factors related to physical activity, television viewing, sleep duration, and meal frequency on body fat (BF) in adolescents. Method: This cross-sectional study comprised 1,310 Spanish adolescents (age 13-18.5 years). Lifestyle variables were self-reported and BF indicators (weight, height, six skinfold thicknesses, waist circumference) measured during the years 2000-2002. Lifestyle risk factors were: physically inactive, $\geq 3 \mathrm{~h} /$ day watching television, $<8 \mathrm{~h} /$ day sleep duration, and $<5$ meals a day. The number of lifestyle risk factors was calculated for each participant, ranging from 0 to 4. Results: The number of lifestyle risk factors was positively associated with sum of six skinfolds, $\% \mathrm{BF}$, waist circumference, and waist-height ratio (all $p<0.001)$. The odds ratios (95\% confidence interval) of overweight (including obesity) for groups with 1, 2, and 3-4 lifestyle risk factors compared with those with 0 were 2.86 (1.77-4.62), 3.61 (2.16-6.04), and 5.81 (3.0710.99 ), respectively ( $p$ for trend $<0.001$ ). All the observations were independent of age, gender, race, socioeconomic status, and fat free mass. Conclusion: The combined influence of four lifestyle risk factors is positively associated with BF and an approximately sixfold risk of overweight in adolescents.

\section{Introduction}

Obesity is considered an independent predictor of all-cause mortality and numerous chronic diseases in adults [1]. In Spain, findings from the AVENA (Alimentación y Valoración del Estado Nutricional de los Adolescentes/Feeding and Assessment of Nutritional Status of Spanish Adolescents) study showed that 1 out of 4 adolescent boys was overweight or obese, whereas 1 out of 5 adolescent girls was at least overweight [2]. Since obese adolescents are likely to become obese adults, obesity in adolescence is one of the main concerns for the Spanish public health system [3].

Secular trends in pediatric obesity during the last decades as well as the concurrent increase in the number of behavioral risk factors from childhood to adulthood suggest a possible cause-effect [4]. Notwithstanding, since obesity is a multifactorial condition [4], new paradigms support a multiple health behavior approach to prevent obesity [5]. This novel perspective highlights the stronger impact of multiple lifestyle behavior strategies rather than single behavior interventions [5].

Nowadays, unhealthy diets and low levels of physical activity are the most recognized lifestyle risk factors related to obesity in youth $[4,5]$. In addition, recent evidence with regard to the damage of increasing sedentary behaviors such as television (TV) viewing and an inadequate sleep time is also gaining importance in public health policies $[6,7]$. Hence, although these four lifestyle risk factors (diet, physical activity, TV viewing, and sleep duration) are related to obesity, the combined influence of these modifiable lifestyle behaviors on obesity in adolescents remains unknown; as a result, they

\section{KARGER}

Fax +497614520714

Information@Karger.de

www.karger.com (c) 2011 S. Karger GmbH, Freiburg

$1662-4025 / 11 / 0042-0105 \$ 38.00 / 0$

Accessible online at:

www.karger.com/ofa 
might have relevant short- and long-term public health implications. Therefore, the aim of this study was to examine the combined influence of lifestyle risk factors related to physical activity, TV viewing, sleep duration, and meal frequency on body fat (BF) in Spanish adolescents.

\section{Participants and Methods}

\section{Participants}

The adolescents for the present study were participants in the AVENA study. The complete and detailed methodology of the AVENA study has been described elsewhere [8]. In brief, the AVENA study was designed to evaluate dietary patterns, body composition, lifestyle habits, health indicators, and genetic markers in a representative sample of adolescents, aged 13-18.5 years, from five Spanish cities (Granada, Madrid, Murcia, Santander, and Zaragoza), during the years 2000-2002. The final sample size stratified by age, sex, geographical location, and type of school was 2,859 . Of the final sample, participants lacking the complete set of anthropometry and lifestyle variables were excluded, and thus, the final sample for this study was 610 adolescent boys and 700 adolescent girls $(\mathrm{n}=$ 1,310). This final sample size also had available data on socioeconomic status (SES) defined by the mother's educational level in four categories (elementary school, middle school, high school, university). Parents and guardians were informed about the nature and purpose of the study, and they gave their written informed consent. The AVENA study protocols were approved by the Review Committee for Research Involving Human Subjects from Marques de Valdecilla University Hospital.

\section{Anthropometry}

Harmonization and standardization of anthropometric measurements within the AVENA study has been detailed elsewhere [9]. Anthropometric measurements were made with participants barefoot and in their underwear. Body mass index (BMI) was calculated as body weight $(\mathrm{kg})$ / height $(\mathrm{m})$ squared. Overweight (including obesity) adolescents were classified according to age- and sex-specific BMI cut-offs proposed by Cole et al. [10]. Skinfold thicknesses were measured at the left side of the body with a Holtain caliper at the following six sites: triceps, biceps, subscapular, suprailiac, thigh, and calf. Waist circumference (WC) was measured with an inelastic tape between the lowest rib and the iliac crest, at the end of a gentle expiration. Percentage of body fat (\%BF) was calculated using Slaughter's equations [11], which have shown reasonable validity to estimate \%BF in Spanish adolescents [12]. Fat free mass (FFM) was estimated from $\% \mathrm{BF}$ and body weight. In this study, the sum of the six skinfold thicknesses (sum6) and \%BF were used as indicators of total $\mathrm{BF}$, whereas $\mathrm{WC}$ and waist-height ratio were used as indicators of abdominal $\mathrm{BF}$.

\section{Lifestyle Behaviors}

Lifestyle behaviors in the AVENA study were self-reported. Leisure time physical activity (LTPA) was determined from the following question: 'Do you undertake any physical sporting activity after school?' Adolescents had to select: i) none; ii) one; iii) more than one. Adolescents' time watching TV was asked as follows: 'How many hours do you usually spend watching TV per day?' Adolescents had to select one of the following categories: i) none; ii) less than $0.5 \mathrm{~h}$; iii) between $0.5-1 \mathrm{~h}$; iv) between $1-3 \mathrm{~h}$; v) between $3-4 \mathrm{~h}$; vi) more than $4 \mathrm{~h}$. In order to assess sleep duration, adolescents answered two questions: i) 'When do you usually go to bed on weekdays?' There were seven possible answers ranging from $\leq 21: 00$ to $\geq 00: 00$, with every category adding $30 \mathrm{~min}$ to the previous one; ii) 'When do you usually get up in the morning on weekdays?' In this question, adolescents had six possible options ranging from $\leq 06: 30$ to $\geq 09: 00$. The sleep duration was calculated by the differ- ence between going to bed and time when getting up. Finally, participants also reported the regularity of eating or not eating the following meals: breakfast, morning snack, lunch, afternoon snack, dinner, and evening snack.

In the current study, lifestyle risk factors were considered as follows: physically inactive (non-LTPA), $\geq 3 \mathrm{~h} /$ day watching TV, $<8 \mathrm{~h} /$ day sleep duration, and $<5$ meals a day. The number of lifestyle risk factors was also calculated for each participant, ranging from 0 to 4 . The categorization of these risk factors was chosen based on previous reports from the AVENA study and public health recommendations [13-15].

\section{Statistical Analysis}

Descriptive characteristics of this study are presented as mean (SD), unless otherwise indicated. Gender differences were analyzed by one-way analysis of variance (ANOVA) for continuous variables and Chi-squared tests for categorical variables. Preliminary analyses showed no significant interactions between gender and lifestyle behaviors or other main factors; therefore, all analyses were conducted with adolescent boys and girls together.

Differences in levels of total (sum6 and \%BF) and abdominal (WC and waist-height) BF for individual lifestyle risk factors (physical activity, TV viewing, sleep time, and number of meals a day) were assessed by analysis of covariance (ANCOVA) adjusted by age, gender, race, SES, and FFM. Similarly, binary logistic regression was performed to examine the odds ratio (OR) and $95 \%$ confidence intervals (CI) of being overweight (including obesity) in those adolescents having individual lifestyle risk factors.

Associations of lifestyle risk factors combined with total and abdominal BF in adolescents were analyzed by linear regression adjusted by potential confounders using four additive models. In addition, differences in total and abdominal BF by number of lifestyle risk factors in adolescents were analyzed by ANCOVA adjusted by the same confounder variables. Finally, binary logistic regression was also performed to examine the ORs and $95 \% \mathrm{CI}$ of being overweight by number of lifestyle risk factors adjusted by confounder variables. All the analyses were conducted using SPSS 15.0 for Windows, and statistical significance was set at $\mathrm{p}<0.05$.

\section{Results}

Sample characteristics and gender differences are depicted in table 1. Overall, adolescent girls had significantly higher levels of total BF than boys, whereas adolescent boys had higher levels of abdominal BF than girls. Moreover, a higher percentage of adolescent boys than girls had overweight or obesity $(p=0.003)$. Gender differences in lifestyle risk factors were also detected for non-participation in LTPA $(\mathrm{p}<0.001)$ and insufficient sleep duration $(\mathrm{p}=0.040)$, but not for TV viewing $(\mathrm{p}=0.650)$ or meal frequency $(\mathrm{p}=0.409)$. Approximately, adolescents with $0,1,2,3$, and 4 lifestyle risk factors were $20 \%$ (164 boys, 100 girls), 44\% (294 boys, 282 girls), $28 \%$ (124 boys, 245 girls), $7 \%$ (25 boys, 69 girls), and $0.5 \%$ (3 boys, 4 girls), respectively.

Table 2 shows the differences in levels of total and abdominal BF for individual lifestyle risk factors independently of age, gender, race, SES, and FFM. Adolescents with lifestyle risk factors in LTPA or TV viewing or meal frequency showed higher levels of total and abdominal BF than adolescents without risk factors (all $\mathrm{p}<0.05$ ), with the exception of a trend for significance $(p=0.094)$ in waist-height ratio levels 
Table 1. Characteristics of the study sample
Table 2. Differences in total and abdominal body fat by individual lifestyle risk factors in adolescents $(\mathrm{n}=1,310)$

\begin{tabular}{lcccr}
\hline & $\begin{array}{l}\text { All }(\mathrm{n}=1,310) \\
(\mathrm{SD})\end{array}$ & $\begin{array}{l}\text { Adolescent boys } \\
(\mathrm{n}=610)(\mathrm{SD})\end{array}$ & $\begin{array}{c}\text { Adolescent girls } \\
(\mathrm{n}=700)(\mathrm{SD})\end{array}$ & $\mathrm{p} \mathrm{sex}$ \\
\hline Age, years & $15.0(1.3)$ & $14.9(1.3)$ & $15.1(1.4)$ & 0.009 \\
Weight, $\mathrm{kg}$ & $59.2(11.5)$ & $63.1(12.6)$ & $55.8(9.2)$ & $<0.001$ \\
Height, cm & $165.9(8.6)$ & $170.9(8.3)$ & $161.5(6.2)$ & $<0.001$ \\
BMI, kg/m ${ }^{2}$ & $21.5(3.4)$ & $21.5(3.5)$ & $21.4(3.2)$ & 0.472 \\
Overweight + obesity, \% & 21 & 24 & 21 & 0.003 \\
Sum of six skinfolds, mm & $86.7(35.0)$ & $74.2(36.3)$ & $97.6(30.0)$ & $<0.001$ \\
Body fat, \% & $22.3(8.3)$ & $19.1(9.4)$ & $25.1(6.0)$ & $<0.001$ \\
Waist circumference, cm & $73.4(8.8)$ & $76.2(9.0)$ & $70.9(7.7)$ & $<0.001$ \\
Waist-height ratio, relative amount & $0.46(0.0)$ & $0.51(0.1)$ & $0.46(0.0)$ & 0.009 \\
Fat free mass, kg & $45.6(7.7)$ & $50.3(7.9)$ & $41.4(4.6)$ & $<0.001$ \\
& & & & 0.023 \\
Maternal education & 37 & 36 & 38 & 0.154 \\
Elementary school, \% & 18 & 18 & 19 & 0.007 \\
Middle school, \% & 24 & 21 & 26 & 0.070 \\
High school, \% & 21 & 25 & 17 & $<0.001$ \\
University, \% & & & & 0.650 \\
Lifestyle risk factors & 33 & 17 & 49 & 0.040 \\
Non-LTPA, \% & 10 & 10 & 20 & 0.409 \\
TV viewing $\geq 3$ h/day, \% & 18 & 60 & 63 & \\
Sleep duration <8 h/day, \% & 62 & & & \\
Meal frequency <5 per day, \% & & 16 & & \\
\hline
\end{tabular}

\begin{tabular}{|c|c|c|c|c|c|}
\hline \multirow[t]{2}{*}{ Lifestyle risk factors } & \multirow[t]{2}{*}{$\mathrm{N}$} & \multicolumn{2}{|l|}{ Total body fat } & \multicolumn{2}{|l|}{ Abdominal body fat } \\
\hline & & $\begin{array}{l}\text { sum of } 6 \text { skinfolds } \\
\text { (SD), mm }\end{array}$ & body fat (SD), \% & $\begin{array}{l}\text { waist circumference } \\
\text { (SD), cm }\end{array}$ & $\begin{array}{l}\text { waist-height ratio }(\mathrm{SD}) \text {, } \\
\text { relative amount }\end{array}$ \\
\hline \multicolumn{6}{|l|}{ LTPA } \\
\hline No (risk) & 447 & $91.06(4.06)$ & $24.10(0.96)$ & $75.14(0.92)$ & $0.46(0.01)$ \\
\hline Yes & 863 & $85.59(4.00)$ & $22.99(0.95)$ & $74.00(0.90$ & $0.45(0.01)$ \\
\hline $\mathrm{p}$ & & 0.008 & 0.022 & 0.014 & 0.094 \\
\hline \multicolumn{6}{|l|}{ Television viewing } \\
\hline$\geq 3 \mathrm{~h} /$ day (risk) & 132 & $94.60(4.71)$ & $25.00(1.12)$ & $76.51(1.06)$ & $0.46(0.01)$ \\
\hline$<3 \mathrm{~h} /$ day & 1,178 & $87.01(3.92)$ & $23.25(0.93)$ & $74.27(0.88)$ & $0.45(0.01)$ \\
\hline $\mathrm{p}$ & & 0.012 & 0.015 & 0.009 & 0.015 \\
\hline \multicolumn{6}{|l|}{ Sleep duration } \\
\hline$<8$ h/day (risk) & 237 & $84.32(4.43)$ & $22.84(1.05)$ & $73.87(1.00)$ & $0.46(0.01)$ \\
\hline$\geq 8 \mathrm{~h} /$ day & 1,073 & $88.51(3.93)$ & $23.57(0.93)$ & $74.58(0.88)$ & $0.45(0.01)$ \\
\hline $\mathrm{p}$ & & 0.080 & 0.200 & 0.183 & 0.606 \\
\hline \multicolumn{6}{|l|}{ Meals frequency } \\
\hline$<5$ a day (risk) & 808 & $92.71(3.86)$ & $24.66(0.91)$ & $75.31(0.88)$ & $0.46(0.01)$ \\
\hline$\geq 5$ a day & 502 & $77.94(4.01)$ & $20.95(0.95)$ & $72.77(0.91)$ & $0.44(0.01)$ \\
\hline $\mathrm{p}$ & & $<0.001$ & $<0.001$ & $<0.001$ & $<0.001$ \\
\hline
\end{tabular}

Analyses were adjusted for age, sex, race, socioeconomic status, and fat free mass. for LTPA groups. There were no significant differences in levels of total and abdominal fat between sleep duration groups ( $p>0.05)$. On the other hand, the ORs (95\% CI) for being overweight in those adolescents with risk factors in LTPA, TV viewing, sleep duration, and meal frequency were 1.268 (0.910-1.766), 1.354 (0.859-2.134), 1.282 (0.881-1.863), and 2.887 (2.049-4.068), respectively.
Table 3 presents the associations of lifestyle risk factors combined with total and abdominal BF. Multiple linear regressions showed that the number of lifestyle risk factors was positively associated with sum6 $(6.497 \mathrm{~mm}, 95 \%$ CI 4.415-8.579), \%BF (1.605\%, 95\% CI 1.112-2.099), WC (1.227 $\mathrm{cm}, 95 \%$ CI $0.756-1.698)$, and waist-height ratio (0.008 relative amount, 95\% CI 0.005-0.011) BF measurements (all 


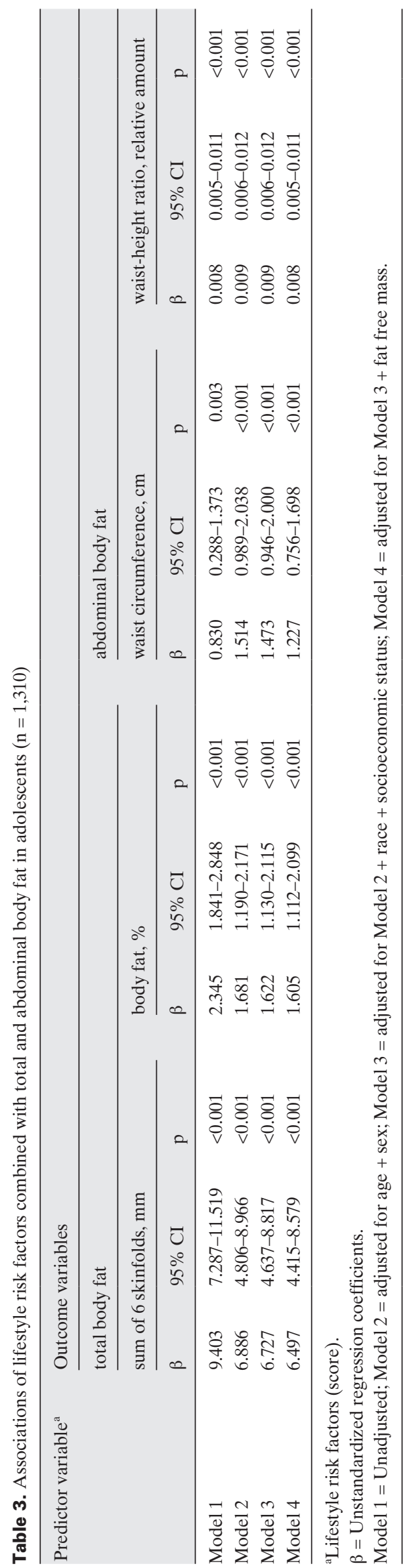

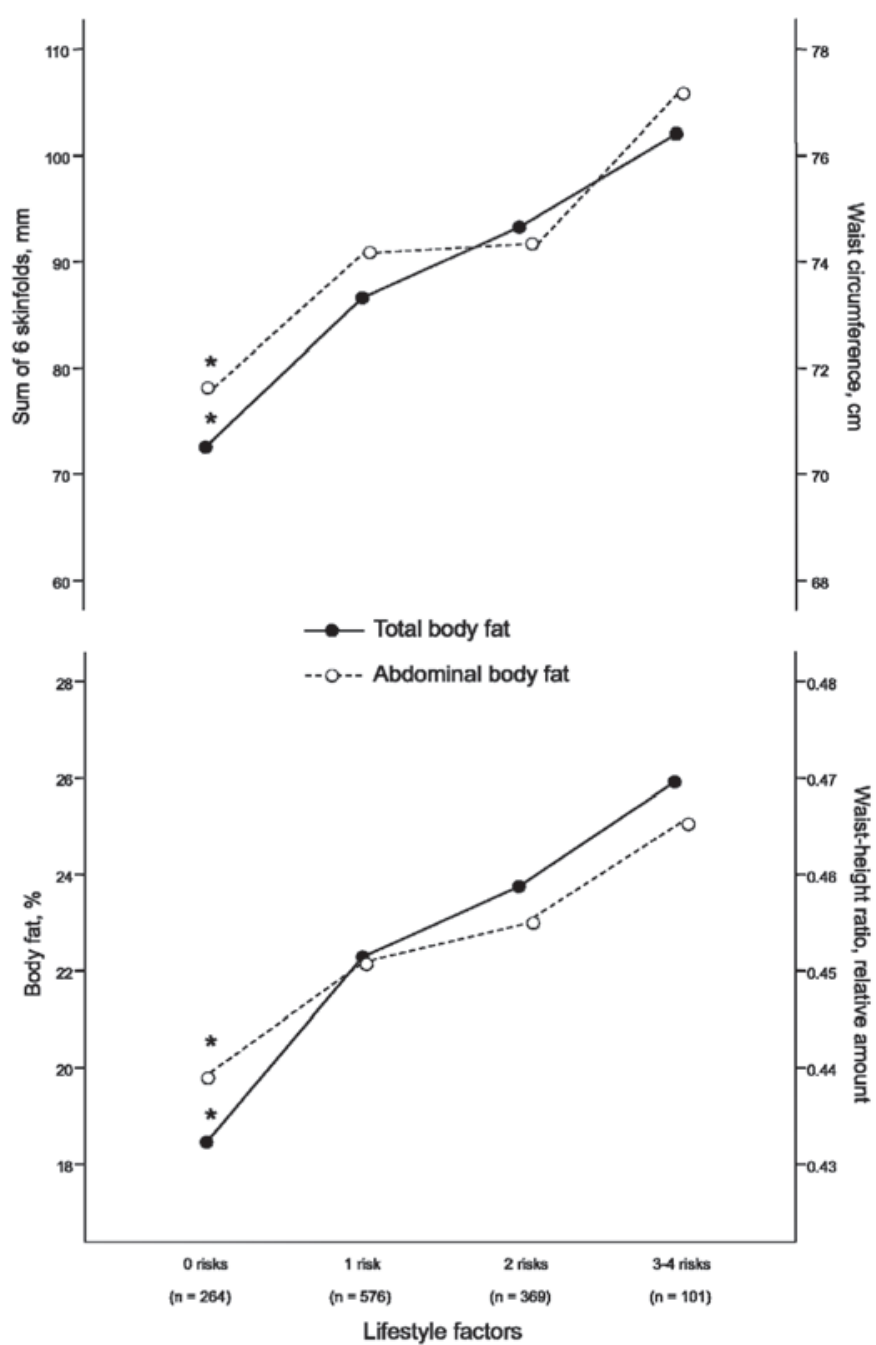

Fig. 1. Differences in total and abdominal body fat by number of lifestyle risk factors in adolescents $(n=1,310)$. Analyses were adjusted for age, gender, race, socioeconomic status, and fat free mass. ${ }^{*} p<0.001$ in comparison with other categories. Total body fat $=$ Sum of six skinfolds and body fat; abdominal body fat = waist circumference and waist-height ratio.

$\mathrm{p}<0.001$ ), independently of age, gender, race, SES, and FFM. Figure 1 shows the differences in levels of total and abdominal BF by number of lifestyle risk factors. Since only $0.5 \%$ of the adolescents had 4 lifestyle risk factors, these statistical analyses were performed with four groups $(0,1,2$, and 3-4 risk factors). ANCOVA showed significant trends in values of total and abdominal BF by number of lifestyle risk factors (all $\mathrm{p}<0.001$ ), independently of potential confounder variables. Indeed, significant differences in all the BF measurements were found between adolescents with 0 lifestyle risk factors and those who had more risk factors (all $\mathrm{p}<0.001$ ). Figure 2 shows that adjusted ORs (95\% CI) for ascending groups of lifestyle risk factors compared with those with 0 risk factors were 2.859 (1.771-4.617), 3.607 (2.156-6.035), and 5.809 (3.071-10.990), respectively ( $\mathrm{p}$ for trend $<0.001$ ). 


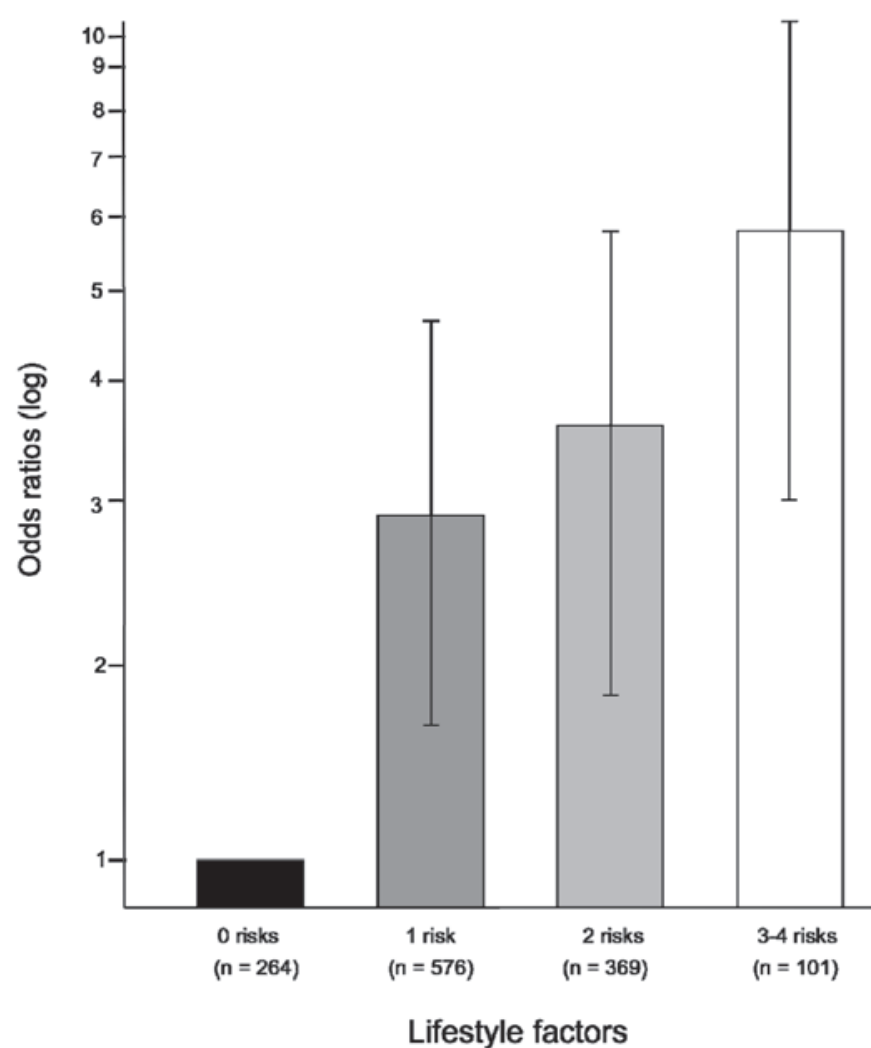

Fig. 2. Odds ratios for being overweight (including obesity) by number of lifestyle risk factors in adolescents $(\mathrm{n}=1,310)$. Analyses were adjusted for age, gender, race, socioeconomic status, and fat free mass. Vertical bars show $95 \% \mathrm{CI}$.

\section{Discussion}

The findings of this study suggest that 4 lifestyle risk factors combined (physical activity, TV viewing, sleep duration, and meal frequency) are positively associated with both total and abdominal BF as well as with a higher risk of being overweight in adolescents, independent of potential confounders. Thus, although physical activity, TV viewing, sleep patterns, and meal frequency have shown to be a key role on obesity, from a public health perspective, promoting a combination of health behaviors might have a major impact to palliate the current increasing pediatric obesity epidemic.

Previous studies in adolescents have shown the combined influence of 2 lifestyle risk factors on $\mathrm{BF}$, but the present study shows the possible combined influence of 4 putative lifestyle risk factors. For example, the study carried out in 13,600 US adolescents by Eisenmann et al. [16] showed that adolescent girls with high rates of TV viewing and low participation in vigorous physical activity had the highest odds of overweight. In addition, intervention studies that focused on combining lifestyle behaviors in youth showed mixed results [17-19]. Nevertheless, there is strong evidence regarding the combined effect of several lifestyle risk factors on relevant health outcomes, such as mortality and the risk of cardiovascular disease events in adults [20-22]. For example, lifestyle behaviors used in the European Prospective Investigation into Cancer and Nutrition (EPIC) study were based on physical activity, alcohol consumption, smoking, and vitamin intake $[21,22]$. The combination of these four lifestyles predicted approximately a four- and a twofold difference in total mortality [21] and incidence of stroke [22] in men and women, respectively.

In the current study, we have observed that adolescents with 0 lifestyle risk factors had significantly lower levels of total and abdominal BF than adolescents with more risk factors. In contrast, the individual influence of lifestyle risk factors on fatness was limited to three behaviors, i.e. physical activity, TV viewing, and meal frequency. Indeed, these observations were more remarkable when we examined the individual and combined influence of lifestyle risk factors and the risk of overweight. Thus, when examining the individual influence of risk factors, only those adolescents who did not meet at least 5 meals a day had significant odds of being overweight. In spite of this fact, adolescents with 3 or 4 lifestyle risk factors had a sixfold risk of overweight compared to those with 0 risk factors.

How lifestyle factors interact with each other for preventing obesity is still not well understood. Several studies in adolescents have thrown light on this issue with contradictory findings [23-25]. Jago et al. [23] examined associations between physical activity and dietary behaviors in UK adolescents. Since both behaviors were weakly related, the authors suggested that interventions should focus on implementing strategies that were independently successful at changing diet or physical activity behaviors either separately or in combination. Taveras et al. [24] pointed out that changes in TV viewing during adolescence were not associated with changes in LTPA. On the contrary, a cross-sectional study by Driskell et al. [25] showed that physical activity and fruit/vegetable consumption declined, while TV viewing increased in adolescents. Therefore, having 1 lifestyle risk factor almost always significantly increased the odds of being at risk for another lifestyle behavior [25]. Further studies with experimental designs are necessary to understand the relationships among multiple lifestyle risk factors and obesity prevention across the lifespan.

Adolescence is a crucial life period and the bridge between childhood and adulthood. Thus, while the child is almost completely influenced by the closest environments (i.e. family, peers, school, community), adolescents begin to take decisions regarding their lifestyle behaviors. This might be the explanation of why, to date, there is little evidence of success in interventions for preventing obesity in children, and even less in adolescents [17-19]. Therefore, healthy lifestyle behaviors should be introduced or included into daily routines from early childhood and major efforts should be devoted to decrease multiple lifestyle risk factors in adolescence. This per- 
spective is in concordance with the present study in adolescents and one study in preschool-aged children [26] where children exposed to the three household routines of regularly eating the evening meal as a family, obtaining adequate sleep duration at night, and having limited TV viewing time approximately had $40 \%$ lower prevalence of obesity than those exposed to none of these routines [26].

The present study supports recent statements based on multiple behavior practices in preventive medicine [5]. We cannot know whether interventions designed to simultaneously change these 4 lifestyle risk factors might be effective. However, our results suggest that adolescents who scored 0 lifestyle risk factors had significantly lower levels of BF and a lower risk of overweight, and hence, multiple behaviors might have a greater impact on obesity. In addition, the four selected lifestyle behaviors are commonly promoted in public health messages focusing on the child's environment [4]. Indeed, public health messages are easily understandable, concise, generalizable, and in agreement with the search for the most cost-effective preventive strategies. Nevertheless, the impact of public health messages on lifestyle changes in children, adolescents, and their environments need further research.

Strengths of our study are the use of different measurements of total and abdominal BF, the inclusion of relevant confounder variables into all the analyses, and the heterogeneous adolescent population from five Spanish cities. Several limitations in the current study should also be acknowledged. The cross-sectional study design limits drawing causal inferences, and prospective as well as prevention studies are needed. Owing to the unfeasibility to use objective instruments in large-scale research, lifestyle variables were selfreported and results must be interpreted with caution. Given the sample size and the low prevalence of adolescents who had 4 lifestyle risk factors, we had to merge the group with three or four behaviors, limiting the possibility to observe differences across the five lifestyle groups (0-4).

In conclusion, the combined influence of 4 lifestyle risk factors (physical activity, TV viewing, sleep duration, and meal frequency) was positively associated with levels of total and abdominal BF as well as with an approximately sixfold risk of overweight in adolescents. Although these results may have relevant implications for future public health strategies, prospective studies are needed to confirm the value of these observations.

\section{Acknowledgement}

We gratefully acknowledge all participating adolescents, and their parents and teachers for their collaboration.

AVENA Study Group: Coordinator: A. Marcos, Madrid. Local coordinators: M.J. Castillo, Granada; A. Marcos, Madrid; S. Zamora, Murcia; M. García Fuentes, Santander; M. Bueno, Zaragoza. Granada: M.J. Castillo, M.D. Cano, R. Sola (Biochemistry); A. Gutiérrez, J.L. Mesa, J.R. Ruiz (Physical fitness); M. Delgado, P. Tercedor, P. Chillón (Physical activity), M. Martín-Matillas, F. Carreño, F.B. Ortega, G.V. Rodríguez, R. Castillo, F. Arellano (Collaborators). Universidad de Granada. 18071 Granada, Spain. Madrid: A. Marcos, M. González-Gross, J. Wärnberg, S. Medina, F. Sánchez-Múniz, E. Nova, A. Montero, B. de la Rosa, S. Gómez, S. Samartín, J. Romeo, R. Álvarez (Coordination, Immunology), A. Álvarez (Cytometric analysis), L. Barrios (Statistical analysis), A. Leyva, B. Payá (Psychological assessment). L. Martínez, E. Ramos, R. Ortiz, A. Urzanqui (Collaborators). Instituto de Nutrición y Bromatología. Consejo Superior de Investigaciones Científicas (CSIC). 28040 Madrid, Spain. Murcia: S. Zamora, M. Garaulet, F. Pérez-Llamas, J.C. Baraza, J.F. Marín, F. Pérez de Heredia, M.A. Fernández, C. González, R. García, C. Torralba, E. Donat, E. Morales, M.D. García, J.A. Martínez, J.J. Hernández, A. Asensio, F.J. Plaza, M.J. López (Diet analysis). Dpto. Fisiología, Universidad de Murcia. 30100 Murcia, Spain. Santander: M. García Fuentes, D. González-Lamuño, P. de Rufino, C. RedondoFiguero, M.J. Noriega, R. Lanza-Saiz, T. Amigo (Genetic study). Dpto. Pediatría, Universidad de Cantabria. 19003 Santander, Spain. Zaragoza: M. Bueno, L.A. Moreno, A. Sarriá, J. Fleta, G. Rodríguez, C.M. Gil, M.I. Mesana, J.A. Casajús, V. Blay, M.G. Blay (Anthropometric assessment). Escuela Universitaria de Ciencias de la Salud, Universidad de Zaragoza. 50009 Zaragoza, Spain.

\section{Disclosure Statement}

The AVENA study was funded by the Spanish Ministry of Health (FIS 00/0015) and grants from Panrico S.A., Madaus S.A., and Procter and Gamble S.A. David Martinez-Gomez was supported by a grant from the Spanish Ministry of Education (AP2006-02464). Luis A. Moreno, Germán Vicente-Rodriguez, and J. Pablo Rey-López were supported by a grant from the Spanish Ministry of Health: Maternal, Child Health and Development Network (RD08/0072).

\section{References}

1 Pischon T, Boeing H, Hoffmann K, et al: Genera and abdominal adiposity and risk of death in Europe. N Engl J Med 2008;359:2105-2120.

2 Moreno LA, Mesana MI, Fleta J, Ruiz JR, González-Gross M, Sarría A, Marcos A, Bueno M; AVENA Study Group: Overweight, obesity and body fat composition in Spanish adolescents. The AVENA Study. Ann Nutr Metab 2005;49:71-76.

3 Neira M, de Onis M: The Spanish strategy for nutrition, physical activity and the prevention of obesity. Br J Nutr 2006;96:S8-11.
4 Lobstein T, Baur L, Uauy R; IASO International Obesity Task Force: Obesity in children and young people: a crisis in public health. Obes Rev 2004;5: S4-104.

5 Prochaska JO: Multiple Health Behavior Research represents the future of preventive medicine. Prev Med 2008;46:281-285.

6 Rey-López JP, Vicente-Rodríguez G, Biosca M, Moreno LA: Sedentary behaviour and obesity development in children and adolescents. Nutr Metab Cardiovasc Dis 2008;18:242-251.
7 McAllister EJ, Dhurandhar NV, Keith SW, et al: Ten putative contributors to the obesity epidemic. Crit Rev Food Sci Nutr 2009;49:868-913.

8 González-Gross M, Castillo MJ, Moreno L, Nova E, González-Lamuño D, Pérez-Llamas F, Gutiérrez A, Garaulet M, Joyanes M, Leiva A, Marcos A: Feeding and assessment of nutritional status of Spanish adolescents (AVENA study). Evaluation of risks and interventional proposal. I. Methodology (article in Spanish). Nutr Hosp 2003;18:15-28. 
9 Moreno LA, Joyanes M, Mesana MI, GonzálezGross M, Gil CM, Sarría A, Gutierrez A, Garaulet M, Perez-Prieto R, Bueno M, Marcos A; AVENA Study Group: Harmonization of anthropometric measurements for a multicenter nutrition survey in Spanish adolescents. Nutrition 2003;19:481-486.

10 Cole TJ, Bellizzi MC, Flegal KM, Dietz WH: Establishing a standard definition for child overweigh and obesity worldwide: international survey. BMJ 2000;320:1240-1243.

11 Slaughter MH, Lohman TG, Boileau RA, Horswil CA, Stillman RJ, Van Loan MD, Bemben DA Skinfold equations for estimation of body fatness in children and youth. Hum Biol 1988;60:709-723.

12 Rodríguez G, Moreno LA, Blay MG, Blay VA, Fleta J, Sarría A, Bueno M; AVENA-Zaragoza Study Group: Body fat measurement in adolescents: comparison of skinfold thickness equations with dual-energy X-ray absorptiometry. Eur J Clin Nutr 2005;59:1158-1166.

13 Vicente-Rodríguez G, Ortega FB, Rey-López JP, España-Romero V, Blay VA, Blay G, MartínMatillas M, Moreno LA; AVENA-Zaragoza Group: Extracurricular physical activity participation modifies the association between high TV watching and low bone mass. Bone 2009;45:925-930.

14 Ortega FB, Ruiz JR, Castillo R, Chillón P, Labayen I, Martínez-Gómez D, Redondo C, Marcos A, Moreno LA; AVENA Study Group: Sleep duration and cognitive performance in adolescence. The AVENA study. Acta Paediatr 2009;99:454-456.
15 González-Gross M, Gómez-Lorente JJ, Valtueña J, Ortiz JC, Meléndez A: The 'healthy lifestyle guide pyramid' for children and adolescents. Nutr Hosp 2008:23:159-168.

16 Eisenmann JC, Bartee RT, Smith DT, Welk GJ, Fu Q: Combined influence of physical activity and television viewing on the risk of overweight in US youth. Int J Obes (Lond) 2008;32:613-618.

17 Summerbell CD, Waters E, Edmunds LD, Kelly S, Brown T, Campbell KJ: Interventions for preventing obesity in children. Cochrane Database Syst Rev 2005;3:CD001871.

18 Connelly JB, Duaso MJ, Butler G: A systematic review of controlled trials of interventions to prevent childhood obesity and overweight: a realistic synthesis of the evidence. Public Health 2007;121:510 517.

19 Gonzalez-Suarez C, Worley A, Grimmer-Somers $\mathrm{K}$, Dones V: School-based interventions on childhood obesity: a meta-analysis. Am J Prev Med 2009; 37:418-427.

20 Knoops KT, de Groot LC, Kromhout D, Perrin AE, Moreiras-Varela O, Menotti A, van Staveren WA: Mediterranean diet, lifestyle factors, and 10-year mortality in elderly European men and women: the HALE project. JAMA 2004;292:1433-1439.
21 Myint PK, Luben RN, Wareham NJ, Bingham SA, Khaw KT: Combined effect of health behaviours and risk of first ever stroke in 20,040 men and women over 11 years' follow-up in Norfolk cohort of European Prospective Investigation of Cancer (EPIC Norfolk): prospective population study. BMJ 2009;338:b349.

22 Khaw KT, Wareham N, Bingham S, Welch A, Luben R, Day N: Combined impact of health behaviours and mortality in men and women: the EPIC-Norfolk prospective population study. PLoS Med 2008;5:e12.

23 Jago R, Ness A, Emmett P, Mattocks C, Jones L, Riddoch C: Obesogenic diet and physical activity: independent or associated behaviours in adolescents? Public Health Nutr 2010;13:673-681.

24 Taveras EM, Field AE, Berkey CS, Rifas-Shiman SL, Frazier AL, Colditz GA, Gillman MW: Longitudinal relationship between television viewing and leisure-time physical activity during adolescence. Pediatrics 2007;119:e314-319.

25 Driskell MM, Dyment S, Mauriello L, Castle P, Sherman K: Relationships among multiple behaviors for childhood and adolescent obesity prevention. Prev Med 2008;46:209-215.

26 Anderson SE, Whitaker RC: Household routines and obesity in US preschool-aged children. Pediatrics 2010;125:420-428. 